\title{
Das Geheimnis der Langeweile
}

\section{Erhard Taverna}

Dr. med., Mitglied der Redaktion

Immerzu geschieht etwas. Wir registrieren Abläufe, spüren Veränderungen und meinen zu wissen, was da vor sich geht. Der rastlos Tätige kommt nicht dazu, über die Zeit nachzudenken. Sie entzieht sich der direkten Wahrnehmung, vielleicht wäre es sogar eine unangenehme Erfahrung. Die tägliche Ereignisdichte schützt uns vor dieser Begegnung. Eine volle Agenda macht uns gewichtig, sie gibt uns Bodenhaftung. Mit einer leeren verlören wir den Grund unter den Füssen, wir wären schwerelos. Das Zeitalter der Maschinen hat die Mentalitäten gründlich verändert. Die Uhr am Handgelenk gibt in der Arbeitswelt den Takt an. Der eingeklemmte Fabrikarbeiter Chaplin wird im Film Modern Times zu einem Teil des riesigen Räderwerks. Die Symbolik hat die Fliessbandarbeit überdauert, doch die Botschaft ist dieselbe: die Diktatur der Ökonomie hat alle Lebensbereiche erfasst, optimierte Prozesse, mehr Effizienz, mehr Ertrag, Stress bis in die oberen Etagen. Man vergleiche nur das Schnitttempo alter Streifen mit aktuellen Aktionsfilmen. Das Publikum wäre früher in Scharen davongelaufen. Ein Burnout bekommt, wer das Arbeitssoll überfüllt hat. Eine anerkannte Krankheit, die zwar nicht mit einem Orden gefeiert wird, aber dennoch einiges mit dem einst gefeierten Stachanow gemeinsam hat. Beide, der sowjetische Kohlenschaufler und sein moderner Nachfolger, enden in einer Nervenanstalt. In der digitalen Welt hat der Druck noch einmal zugenommen. Entschleunigung ist das Zauberwort. Slow Food gegen Fast Food, Slow Science gegen Publish or Perish. Ein österreichischer Professor hat 1990 den Verein zur Verzögerung der Zeit gegründet, ein internationales Netzwerk, das einen bewussteren Umgang mit der Zeit anstrebt. Interventionen im öffentlichen Raum sollen zum Nachdenken provozieren, etwa mit einem Unesco-Tag des Fotofastens am Chiemsee oder mit einer Meldestelle für Glücksmomente in der Ostschweiz. Alles gut und recht, wenn es auch dazu anregt nicht, nur über die Beschleunigung, sondern auch über die Zeit an sich nachzudenken. Dabei kennt jeder Konsument der Eventgesellschaft den Zustand der Langeweile. Die Zeit vergeht ereignislos, sie dehnt sich scheinbar end- und sinnlos. Für die meisten Menschen ist das ein experimentell vielfach belegter Horror. Nichtstun, Stillsitzen, ohne Zerstreuung sich selber ausgesetzt sein, ist schwierig zu ertragen. Ein Ausnamezustand mit einem schlechten Ruf. Der Psychiater Daniel Hell befasste sich eingehend mit dem Leben der frühchristlichen Wüstenmönche. Wenn der Mittagsdämon, die Akedia, die Eremiten heimsuchte, war die Zeit wie angehalten, zähflüssig wie Galle. Ekel, Langeweile und Überdruss, gepaart mit einer inneren Unruhe, gefährdeten die Meditation. Im Mittelalter wurde aus der Akedia die Todsünde der Trägheit. Existenzialisten wie

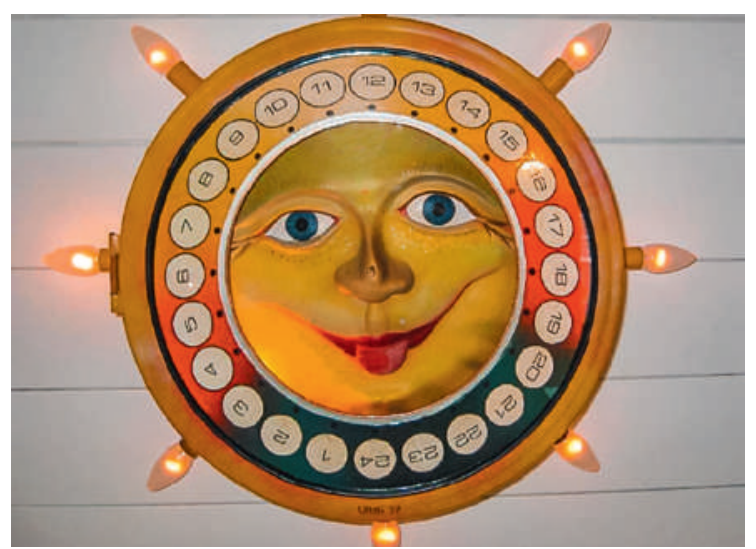

Ein Kunstwerk von Thomas Urben, der Zeit gewidmet.

Sartre oder Camus erleben den Ekel und die Absurdität als Daseinserfahrung. Viele Philosophen, von Pascal bis zu Heidegger, haben die Langeweile als Antipode der Betriebsamkeit analysiert. Sie interpretierten diese Erfahrung zunehmend auch positiv, als Zugang zum Mysterium der Zeit. Ein existenzieller oder gar metaphysischer Zustand.

In seinem neuen Buch Zeit [1] beschreibt Rüdiger Safranski, wie bei den Romantikern die Karriere der Langeweile als grosses Thema der Moderne ihren ersten Auftritt hat. Heidegger entdeckt im Nichts der Langeweile die Abgründigkeit der Zeit. Wer den Schrecken aushält, erfährt etwas von ihrem eigentlichen Wesen. In dieser persönlichen Erfahrung liegt die Chance zur Verwandlung. Folgerichtig handelt das nächste Kapitel im Buch von der Zeit des Anfangens. Der Autor hat sein Ziel klar formuliert: «Ich nähere mich der Zeit auf der Spur ihrer Wirkungen, ich beschreibe also, was sie mit uns macht und was wir aus ihr machen.» Das Phänomen der Zeit hat von Plotin bis Einstein, von Augustins Bekenntnissen bis zum thermodynamischen Entropiebegriff die klügsten Köpfe beschäftigt. Dementsprechend gibt es dazu eine unüberschaubare Literatur, die zu bewältigen keine menschliche Eigenzeit ausreichen würde. Rüdiger Safranski, der vielfach preisgekrönte Autor von Biographien über Schopenhauer, Goethe, Schiller, Hoffmann, Nietzsche und Heidegger hat mit Zeit ein Werk verfasst, das gestressten Zeitgenossen ein Kompendium dessen bietet, was sie schon immer wissen wollten oder sollten. Zehn Kapitel führen über die vergesellschaftete und die Weltraumzeit zur unausweichlichen Gewissheit, dass die eigene Anwesenheit einmal zu Ende geht. Langeweile als Einstieg in die Vielfalt der Zeitphänomene. Ein kluger Schachzug, kenntnisreich, gut verständlich und spannend erzählt. Ein kluges, ein unentbehrliches Buch. 